\title{
Study of the Qualitative Composition and Quantitative Content of Parthenolide in the Feverfew (Tanacetum Parthenium) Herb Cultivated In Ukraine
}

Abstract Feverfew is a well-known medicinal plant as a source of the sesquiterpene lactones, the main one is a parthenolide (about $85 \%$ ). Owing to the parthenolide, feverfew herb has anti-inflammatory activity and it is widely used for prevention of migraine. The aim was to study the qualitative composition and quantitative content of the parthenolide in the samples of the feverfew herb cultivated in Ukraine and to study the influence of environmental factors on the accumulation of parthenolide.

Methods. The identification in the samples of the feverfew herb by the thin-layer chromatography method was carried out on silica gel 60 F254 plates, Merck. For the quantitative determination of the parthenolide, a high-performance liquid chromatography ProStar equipped with a diode-matrix detector, were used.

Results. The chromatographic profile of the samples of the feverfew herb was studied using a TLC method. In the chromatograms of test solutions from all samples, the blue zones were detected at the level of parthenolide. The quantitative content of parthenolide ranged between $0.16 \%$ and $0.39 \%$. The highest content was observed in the sample from the Central region of Ukraine. The data obtained indicate that the optimal conditions for parthenolide accumulation in feverfew herb are as follows: black soils, solar insolation not higher than $5.25 \mathrm{kWh} / \mathrm{m} 2 /$ day, average air temperature from $+20^{\circ} \mathrm{C}$ to $+25^{\circ} \mathrm{C}$. All the calculated validation parameters of the parthenolide quantitative determination method meet the necessary acceptance criteria.

Conclusion. The study of the qualitative composition and quantitative content of parthenolide in the samples of feverfew herb cultivated in different regions of Ukraine has been conducted. According to the methodology of Eur.Ph. and SPhU, a parthenolide was identified in all the samples. HPLC method was used to determine the quantitative content of parthenolide in the samples studied. The optimal conditions for parthenolide accumulation in feverfew herb were established.

Keywords Feverfew-parthenolide-thin-layer chromatography-high-performance liquid chromatography-environmental conditions

\section{INTRODUCTION}

A search for new biologically active substances (BAS) is an urgent task for pharmaceutical science. Recently, there has been a growing interest in a group of natural compounds called sesquiterpene lactones. Sesquiterpene lactones cause a wide range of biological effects such as antibacterial, antiinflammatory, cytostatic, fungicidal. Chemically, they are classifiedaccording to the degree of carbon skeleton cyclization. The most common among them include monocyclic ones, namely germacranolides, xantanolides, and elemanolides, as well as bicyclic ones, namely eudesmanolides, guaianolides, and pseudoguaianolides. Among the above-mentioned sesquiterpene $y$-lactones, it is monocyclic germacranolides that are more often found in plants (more than 600 compounds of this class are known) (Konovalova et al., 2008). Methods for extraction of sesquiterpene lactones from plants are quite diverse due to their physical and chemical characteristics, as well as their location in the plants. Sesquiterpene lactones are most often extracted from leaves and flowers of the plants, and less often from roots and bark (Erasto et al., 2006; Youn et al., 2012). Polar and nonpolar solvents are used for extraction. Ethanol, methanol, chloroform, diethyl ether, and various mixtures thereof can act as extractants.

\section{*E-mail:95karisha95@gmail.com}

O Open Access. ๑ 2020 European Pharmaceutical Journal, published by Sciendo. (cc)BY-NC-ND This work is licensed under the Creative Commons Attribution-NonCommercialNoDerivatives 3.0 License. 
Sesquiterpene lactones attract the attention of scientists in many countries as they are found in plant sources of such families as Asteraceae, Amaranthaceae, Apiaceae, Lauraceae, Magnoliaceae, and Lamiaceae, as well as in some species of fungi and mosses. One of the sources of this BAS group is a representative of the Asteraceae family, feverfew (Tanacetum parthenium (L.) Schultz Bip.). It is a perennial herb, also known as Chrysanthemum parthenium (L.) Bernh., Leucanthemum parthenium (L.) Gren and Gordon, Pyrethrum parthenium (L.) Smith, Matricaria eximia Hort., Matricaria parthenium (L.) Smith. It is widely cultivated in Europe, North America, and Ukraine as an ornamental and honey-bearing plant, but it has found a wide use in medicine abroad as an anti-inflammatory, antipyretic, and cytostatic agent (Pareek et al., 2011). The main indications for the use of feverfew herb are inflammatory diseases of the connective tissue, gynaecological diseases, and migraines. The biological effect of this plant is mainly due to sesquiterpene lactones, about 30 of which are present in it. Among the sesquiterpene lactones of feverfew, about $85 \%$ is parthenolide that belongs to the class of germacranolides. Other sesquiterpene lactones are found in fewer amounts, they are chrysanthemum, artecanin, artemorin, balchanin, canin, 10-epicanin, epoxyartemorin, santamarin, epoxysantamarin, and so on (Konovalova et al., 2008).

The accumulation of BAS is influenced by environmental factors, first of all, air temperature, precipitation, solar insolation, and soil composition. A separate important factor for the harvesting of medicinal plant raw materials with the highest BAS content is the vegetation phase. According to the literature, the vast majority of medicinal plant raw material is harvested during the period of mass flowering (Zolotaykina et al., 2016; Feduraev et al., 2019). Accumulation of parthenolide has been previously studied by foreign researchers. For example, Awang V.C. has studied the accumulation of parthenolide in a mixture of leaves and flowering tops and separately in the leaves and flowering tops of feverfew by HPLC. The content of parthenolide in the mixture of leaves and flowering tops was $0.18 \%, 0.09 \%$ in leaves, and $0.27 \%$ in flowering tops (Awang et al., 1991). Hendricks $\mathrm{H}^{\left[{ }^{[8]}\right.}$ has analysed the content of parthenolide accumulation in feverfew herb during the vegetation season. The content of parthenolide ranged from $0.29 \%$ to $0.92 \%$ and the highest content was observed at the beginning of flowering (Hendricks et al., 1997). According to the research of Avula B., the content of parthenolide in feverfew herb collected in different regions ranged from $0.25 \%$ to $0.28 \%$ (Avula et al., 2006).

Monograph 'Tanaceti parthenii herba" is presented in the European, American, American herbal, and British Pharmacopoeias, as well as in the State Pharmacopoeia of Ukraine (SPhU) (Eur.Ph. 9 ${ }^{\text {th }}, 2013$; Br.Ph. III, 2009; AHPh, 2011; USP 30 ${ }^{\text {th }}, 2007$; SPhU II, 2014). The SPhU monograph on feverfew herb is fully harmonized with the European Pharmacopoeia (Eur.Ph.), but studies of domestic raw materials for compliance with the requirements of this monograph have not been conducted yet. According to the monograph, the identity and quality of medicinal plant raw materials are determined by morphological and anatomical features, qualitative composition, and quantitative content of sesquiterpene lactone, parthenolide.

The purpose of the study was to study the qualitative composition and quantitative content of parthenolide in the samples of feverfew cultivated in Ukraine, as well as to study the influence of environmental factors on the accumulation of parthenolide.

\section{MATERIALS AND METHODS}

The objects of the study were sample batches of feverfew herb collected in Kharkiv (Rs 868), Zhytomyr (Rs 864), Cherkasy (Rs 865), Sumy (Rs 866), Dnipropetrovsk (Rs 867), Poltava (Rs 869), and Kyiv (Rs 870) regions during the mass flowering period in 2018. Samples for analysis were prepared by collecting and combining three individual plants as one sample from a specific area.

The batches of medicinal plant raw materials are registered in the State Enterprise 'Ukrainian Scientific Pharmacopoeia Centre for Quality of Medicines.'

Identification of parthenolide was performed by TLC using the method given in 'Feverfew' monograph of the European Pharmacopoeia (Eur.Ph.) and 'Feverfew' monograph of the SPhU 2.0 (Eur.Ph. 9 ${ }^{\text {th }}, 2013$, SPhU II, 2014). The studies were performed using chromatography plates TLC silica gel 60 F254 (Merck).

For identification and quantitative determination, a standard sample of parthenolide by Sigma-Aldrich, Germany (lot no. 1002453389 , content $\geq 98 \%$ ) was used. For identification of parthenolide in feverfew herb, a reference solution was prepared at a concentration of $1 \mathrm{mg} / \mathrm{mL}$ in methanol. The test solution was prepared by mixing $1 \mathrm{~g}$ of the powdered raw material (355- $\mu \mathrm{m}$ sieve) in $20 \mathrm{ml}$ of methanol and heating it in a water bath at $60^{\circ} \mathrm{C}$ for 15 minutes. The resulting solution was cooled, filtered, and evaporated under reduced pressure, after which the remainder was dissolved in $2 \mathrm{~mL}$ of methanol. A 15:85 acetone/toluene mixture was used as mobile phase. The solutions for analysis were applied in strips 10 $\mathrm{mm}$ long and the volume of $20 \mathrm{~mL}$. For development, the chromatography plate was sprayed with a solution of $5 \mathrm{~g} / \mathrm{L}$ of vanillin in a mixture of 20 volumes of ethanol and 80 volumes of sulfuric acid.

Determination of the quantitative content of parthenolide in feverfew herb was performed using a high-performance liquid chromatograph ProStar, equipped with a diode-matrix detector PDA 330 (Varian, the USA), according to the method described in 'Feverfew' monographs of the Eur.Ph. and SPhU 2.0 (Eur.Ph. $9^{\text {th }}, 2013$, SPhU II, 2014). To determine the content of parthenolide, a column Purospher ${ }^{\circledR}$ STAR RT-18e, Hibar ( $250 \times 4.0 \mathrm{~mm}$, particle size $5 \mu \mathrm{m}$ ) by Merck was used. Mobile phase: a mixture of acetonitrile and water (40:60), elution type: isocratic. Separation was performed at a flow rate of 
Table 1. Results of quantitative determination of parthenolide in batches of feverfew herb.

\begin{tabular}{|c|c|c|c|c|}
\hline Batch No. & $\begin{array}{l}\text { The region of collection of } \\
\text { raw materials }\end{array}$ & Requirements, \% & $X_{\text {avr }} \pm_{\Delta} X, \%$ & $\begin{array}{l}\text { Criterion } \\
\text { satisfaction }\end{array}$ \\
\hline Rs 864 & Zhytomyr region & \multirow{7}{*}{$\geq 0.2$} & $0.22 \pm 0.01$ & Satisfied \\
\hline Rs 865 & Cherkasy region & & $0.16 \pm 0.06$ & No satisfied \\
\hline Rs 866 & Sumy region & & $0.27 \pm 0.11$ & Satisfied \\
\hline Rs 867 & Dnipropetrovsk region & & $0.26 \pm 0.09$ & Satisfied \\
\hline Rs 868 & Kharkiv region & & $0.22 \pm 0.02$ & Satisfied \\
\hline Rs 869 & Poltava region & & $0.24 \pm 0.04$ & Satisfied \\
\hline Rs 870 & Kyiv region & & $0.39 \pm 0.10$ & Satisfied \\
\hline
\end{tabular}

Note. $X_{\text {avr }}$-average value; $X$ - half-wight of confidence interval

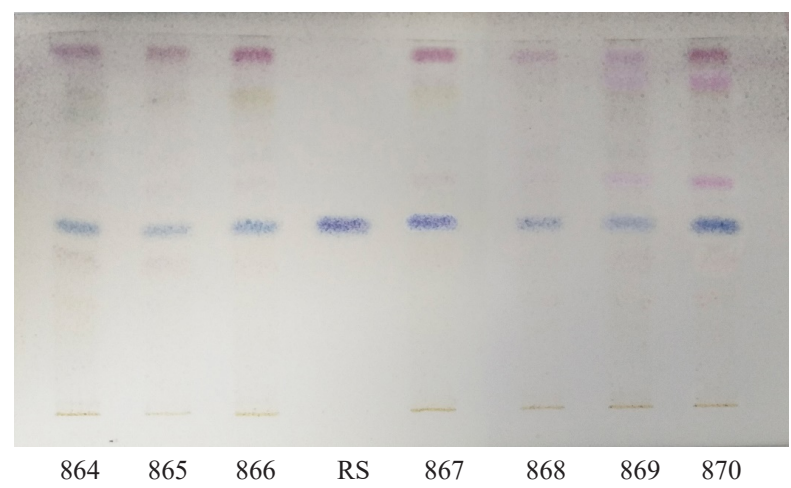

Figure. 1. TLC of feverfew herb batches and parthenolide reference sample (RS).

$1 \mathrm{~mL} / \mathrm{min}$. The injection volume was $20 \mu \mathrm{l}$. The detection was performed at a wavelength of $220 \mathrm{~nm}$. Acetonitrile and methanol by Sigma-Aldrich (Germany) with 'gradient grade, for HPLC' qualification and water for chromatography were used for analysis.

Test solution. About $50 \mathrm{~g}$ of the tested raw material $(355-\mu \mathrm{m}$ sieve) was powdered. $1.00 \mathrm{~g}$ of powdered raw material after homogenization was placed into a flask. After adding $40 \mathrm{~mL}$ of methanol, it was heated in a water bath at a temperature of $60^{\circ} \mathrm{C}$ for 10 minutes, then it was cooled and filtered. The filter was washed with $15 \mathrm{~mL}$ of methanol R. $40 \mathrm{~mL}$ of methanol was added to the remainder, the procedure was repeated, the filtrates and washings were combined, and were evaporated to dryness under reduced pressure. The residue was dissolved in methanol $R$ and the volume of the solution was made up to $20.0 \mathrm{~mL}$ with the same solvent. $10.0 \mathrm{~mL}$ of the resulting solution was made up to $50.0 \mathrm{~mL}$ with mobile phase.

Reference solution. $5.0 \mathrm{mg}$ of parthenolide RS was dissolved in methanol and the volume of the solution was made up to $10.0 \mathrm{~mL}$ with the same solvent. $2.0 \mathrm{~mL}$ of the resulting solution was made up to $50.0 \mathrm{~mL}$ with mobile phase.

Before chromatography, solutions were filtered through membrane filters with a pore size of no more than $0.45 \mu \mathrm{m}$. The content $(X)$ of parthenolide, in per cent, is calculated by the following formula:

$\mathrm{X}=\frac{A_{1} * m_{2} * 40}{A_{2} * m_{1}}$

where:

$A_{1}$ is the area of parthenolide peak in the chromatogram of the test solution;

$A_{2}$ is the area of parthenolide peak in the chromatogram of the reference solution;

$m_{1}$ is the exact weight of the raw material used for the preparation of the test solution, in $\mathrm{g}$;

$\mathrm{m}_{2}$ is the weight of parthenolide in the reference solution, in $\mathrm{g}$.

\section{RESULTS AND DISCUSSION}

A method of thin-layer chromatography was used to identify parthenolide in the samples of feverfew herb cultivated in different regions of Ukraine. The results of the study are shown in Figure 1.

As seen from the chromatogram presented, in the central part of the chromatogram, a blue zone is identified at the level of the main zone in the chromatogram of parthenolide reference sample in all the studied samples of the herb. The colour intensity of the identified zones of the corresponding compounds is approximately the same.

During the quantitative determination of parthenolide in the studied samples by HPLC, it is found that the retention time of parthenolide under the described conditions is approximately 16.3 minutes. Typical chromatograms of the reference solution and the test solution are shown in Fig. 2 and 3. 
Eur. Pharm. J. 2020, 67(2), 27-33.

Study of the Qualitative Composition and Quantitative Content of Parthenolide in the Feverfew ...

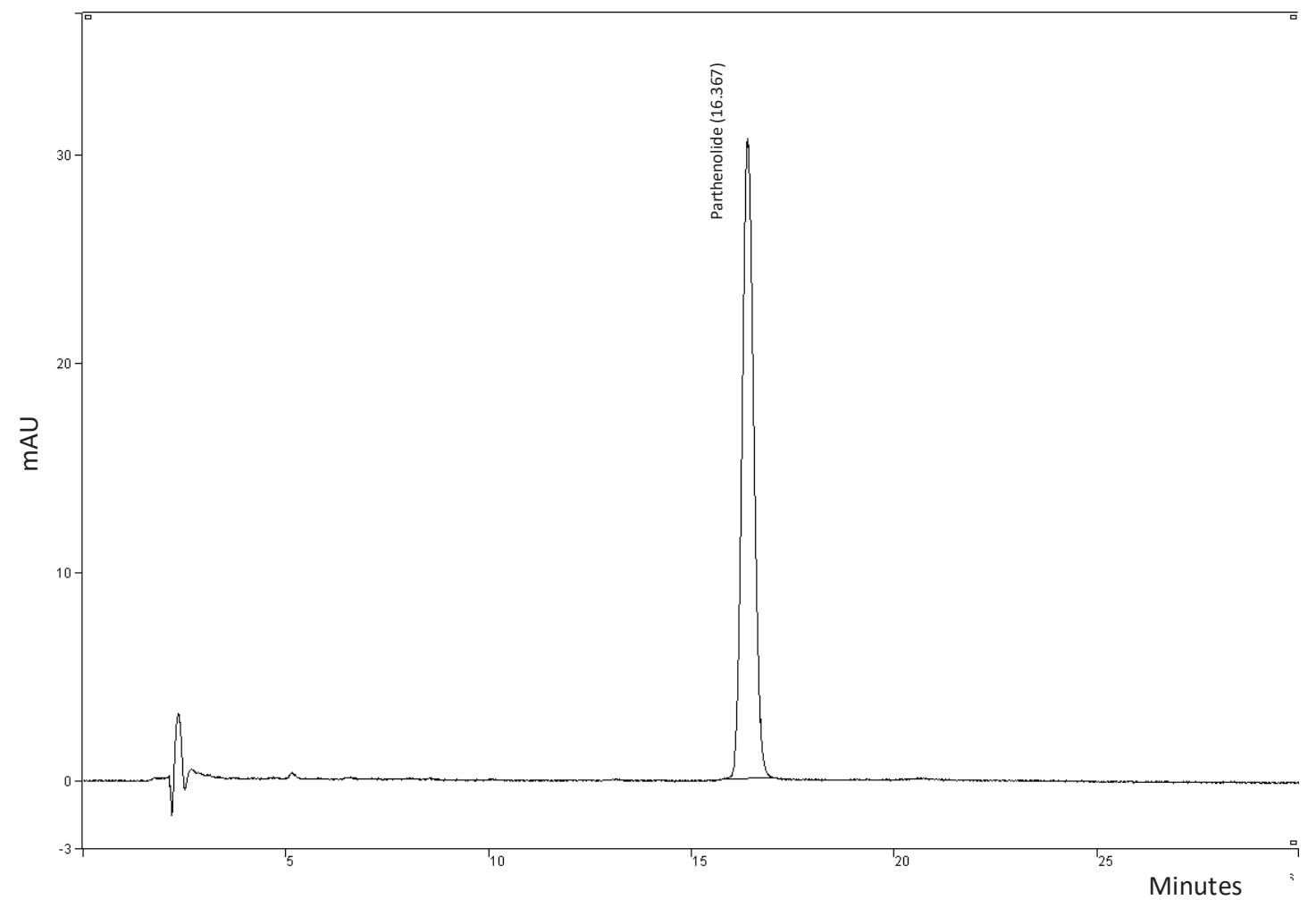

Figure 2. Chromatogram of parthenolide reference solution.

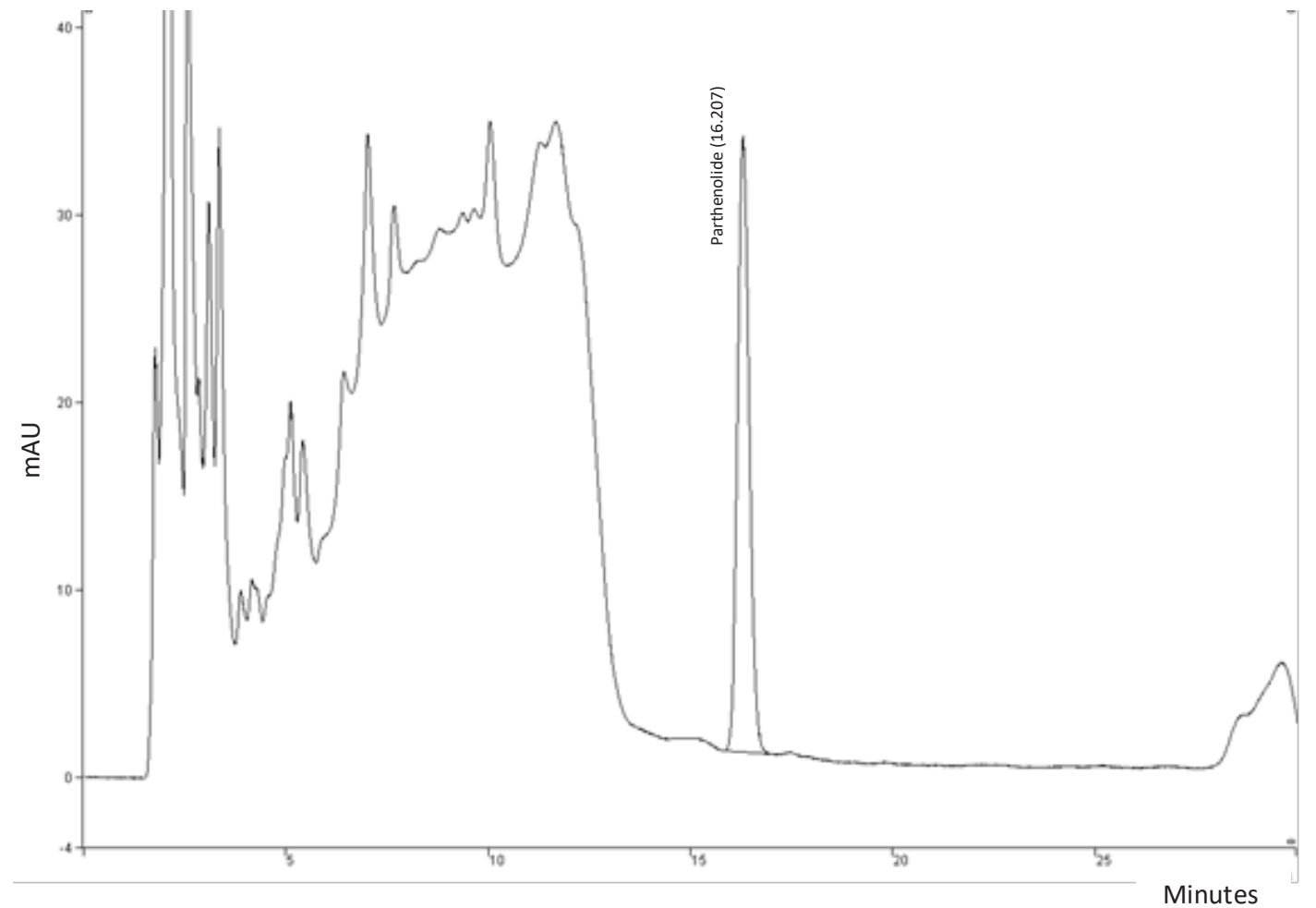

Figure 3. Chromatogram of the test solution. 


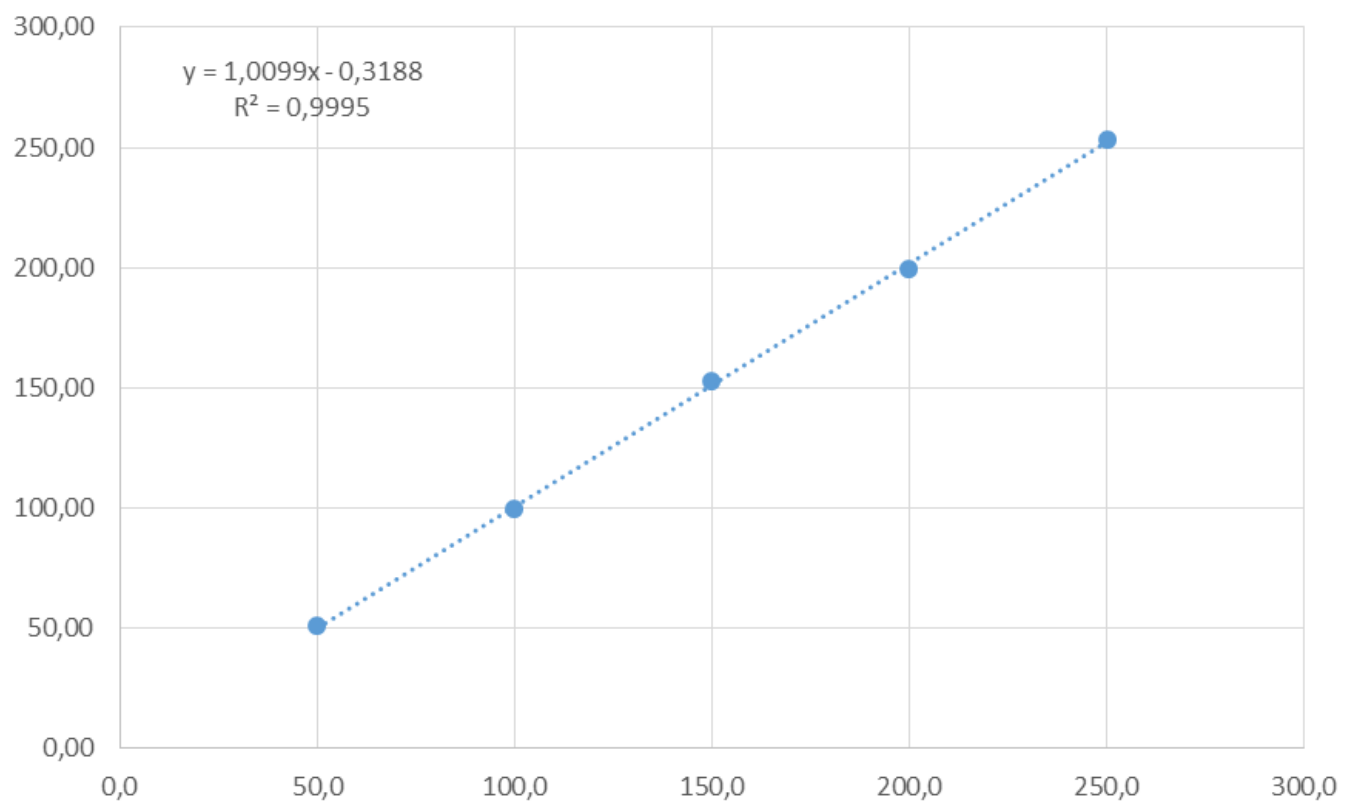

Figure 4. Graph of linear dependence $Y i=b * X i+a$ for parthenolide reference solution.

Table 2. The linearity parameters of the quantitative determination method.

\begin{tabular}{|c|c|c|c|}
\hline Parameter & Requirements & Received value & Criterion satisfaction \\
\hline$|\mathrm{a}|$ & $\leq 4.096$ & 0.32 & Satisfied \\
$\mathrm{S}_{0}$ & $\leq 2.72$ & 2.57 & Satisfied \\
$\mathrm{r}$ & $>0.9821$ & 0.9998 & Satisfied \\
\hline
\end{tabular}

The results of quantitative determination of parthenolide in samples of feverfew herb are shown in Table 1.

To confirm the reliability of the obtained analysis results of parthenolide quantitative content in the samples of feverfew herb, we verified the quantitative determination method according to the following parameters: linearity, accuracy, and precision.

The method of quantitative determination should be linear within the range of application, which should overlap the possible values of the active substance concentrations. In accordance with the requirements of the SPhU, the range of application of the quantitative determination method for parthenolide should be between 50 and $250 \%$ compared to the content claimed $(0.01-0.05 \mathrm{mg} / \mathrm{ml})$.

To confirm the linearity of the method, 5 model solutions of parthenolide were prepared, the concentration of which varied evenly within the range of application (a step of 50\%).

Fig. 4 shows a graph of the linear dependence of parthenolide peak area on the actual concentration of the solution, constructed in normalized coordinates.

The acceptance criteria are calculated in accordance with the requirements of SPhU 2.0 and are shown in Table 2.

The results obtained confirm that the method for quantitative determination of parthenolide in the concentration range between $50 \%$ and $250 \%$ is linear.
To calculate accuracy and precision, the overall uncertainty of the analysis method was determined. According to the requirements of SPhU 2.0 for quantitative determination (one-way normalization 'at least'), the maximum allowable uncertainty of the analysis method is $\max \Delta_{A S} \leq 6.4 \%$. The accuracy and precision criteria were determined in accordance with the requirements of SPhU 2.0 monograph 5.3.N. 2. 'Validation of analytical methods and tests.' The results are shown in Table 3.

The method for determining parthenolide meets the criteria for acceptance of the validation indicator'accuracy' according to two criteria. The method is characterized by sufficient convergence, since the determined value of the relative confidence interval of the parameter $(2.83 \%)$ is less than the critical value for the convergence of results (6.4\%) and meets the criteria for acceptance of the validation indicator 'precision.'

According to the purpose, the next step was to study the influence of environmental factors on the accumulation of parthenolide in the domestic samples of feverfew raw materials. Climatic and edaphic conditions of the regions during the growing season are shown in Table 4.

According to the results of quantitative determination of parthenolide samples of feverfew herb grown in Ukraine, the highest content was observed in the sample from the 
Table 3. The results of the evaluation of the accuracy and precision of the HPLC method.

\begin{tabular}{|c|c|c|c|c|}
\hline \multirow[b]{2}{*}{ Parameter } & \multirow[b]{2}{*}{ Index } & \multicolumn{2}{|c|}{ Criterion } & \multirow[b]{2}{*}{ Criterion satisfaction } \\
\hline & & $\begin{array}{c}\text { Requirements for } \\
\text { statistical insignificance }\end{array}$ & $\begin{array}{c}\text { Requirements for practical } \\
\text { insignificance }\end{array}$ & \\
\hline & 0.79 & $\leq 1.26 \%$ & $\leq 2.048 \%$ & Satisfied \\
\hline$\Delta \mathrm{Z}$ & 2.83 & \multicolumn{2}{|c|}{$\leq 6.4 \%$} & Satisfied \\
\hline
\end{tabular}

Table 4. Climatic and edaphic conditions of the regions during the growing season of feverfew herb

\begin{tabular}{|c|c|c|c|c|}
\hline $\begin{array}{c}\text { The region of collection } \\
\text { of raw materials }\end{array}$ & Soil & $\begin{array}{c}\text { Solar insolation, } \\
\mathbf{k W h} \mathbf{m} \mathbf{2} / \mathbf{d a y}\end{array}$ & Air temperature, ${ }^{\circ} \mathbf{C}$ & Precipitation, $\mathbf{m m}$ \\
\hline Zhytomyr region & black & $3.10-5.21$ & $+21-+26$ & $55-85$ \\
\hline Cherkasy region & sod-gley / sod-podzolic & $3.99-5.54$ & $+20-+25$ & $52-73$ \\
\hline Sumy region & black & $3.12-5.24$ & $+22-+33$ & $50-75$ \\
\hline Dnipropetrovsk region & black & $3.11-5.22$ & $+22-+30$ & $51-74$ \\
\hline Kharkiv region & black & $3.12-5.25$ & $+19-+24$ & $55-85$ \\
\hline Poltava region & black & $3.13-5.23$ & $+21-+26$ & $50-69$ \\
\hline Kyiv region & black & $3.12-5.25$ & $+20-+25$ & $50-70$ \\
\hline
\end{tabular}

Central region of Ukraine, namely Kyiv region, and was 0.39 $\%$, which is probably due to soil composition and moderate environmental conditions. For example, in Kyiv region, black soils predominate, as well as during the growing season of feverfew herb, solar insolation indicators ranged from 3.12 to $5.25 \mathrm{kWh} / \mathrm{m} 2 /$ day, the air temperature ranged from $+20^{\circ} \mathrm{C}$ to $+25^{\circ} \mathrm{C}$, and the amount of precipitation ranged from 50 to $70 \mathrm{~mm}$. The sample from Sumy region had a parthenolide content 1.4 times less than the sample from Kyiv region, and was $0.27 \%$, which could be affected by higher air temperature, namely between $+22^{\circ} \mathrm{C}$ and $+33^{\circ} \mathrm{C}$, and more precipitation: 50 to $75 \mathrm{~mm}$. Approximately at this level, the content of parthenolide was observed in the sample from Dnipropetrovsk region, $0.26 \%$. In the samples from Kharkiv and Zhytomyr regions, the content of parthenolide was observed at the same level of $0.22 \%$, which was 1.7 times less than in the sample from Kyiv region. During the vegetation season, there was an increased amount of precipitation in these regions, namely 55 to $85 \mathrm{~mm}$. The lowest parthenolide content was determined in the sample from Cherkasy region, which may be associated with sod-gley and sod-podzolic soils in this region, as well as the highest solar insolation index, namely 3.99 to $5.54 \mathrm{kWh} / \mathrm{m} 2 /$ day. The data obtained indicate that the optimal conditions for parthenolide accumulation in feverfew herb are as follows: black soils, solar insolation not higher than $5.25 \mathrm{kWh} / \mathrm{m} 2 /$ day, average air temperature from $+20^{\circ} \mathrm{C}$ to $+25^{\circ} \mathrm{C}$, and average precipitation not more than 70 $\mathrm{mm}$. Compliance with these conditions during cultivation may contribute to a higher content of parthenolide in feverfew herb.

\section{CONCLUSIONS}

For the first time, the study of the qualitative composition and quantitative content of parthenolide in the samples of feverfew herb cultivated in different regions of Ukraine has been conducted. According to the methodology of Eur. $\mathrm{Ph}$. and SPhU, a sesquiterpene lactone parthenolide was identified in all raw material samples. HPLC method was used to determine the quantitative content of parthenolide in the samples studied. The quantitative content of parthenolide ranged between $0.16 \%$ and $0.39 \%$. The obtained results of the analysis of 6 batches of raw materials indicate compliance with the requirements of the Eur.Ph. and SPhU according to parameters 'Identification C' and 'Assay.' A batch of herbs harvested in Cherkasy region (batch Rs 865 ) did not meet the requirements of the monograph 'Feverfew' as for indicator 'Assay,' which may be due to the natural and climatic conditions during its cultivation.

All the calculated validation parameters of the parthenolide quantitative determination method meet the necessary acceptance criteria. 
[1] Konovalova DS, Konovalov DA. Sesquiterpene lactones of the feverfew as biologically active substances. Human ecology. 2008;3:3-7.

[2] Erasto P, Grierson DS, Afolayan AJ. Bioactive sesquiterpene lactones from the leaves of Vernonia amygdalina. J of Ethnopharmacology. 2006;106,1:117-120.

[3] Youn UJ, Park EJ, Kondratyuk TP, Simmons CJ, Borris RP, Tanamatayarat $\mathrm{P}$ et al. Anti-inflammatory sesquiterpene lactones from the flower of Vernonia cinerea. Bioorg Med Chem Lett. 2012;1;22(17):5559-5562.

[4] Pareek A, Suthar M, Rathore S, Bansal V. Feverfew (Tanacetum partheniumL.): A systematic review. Pharm. Rev. 2011;5(9):103110.

[5] Zolotaykina MYu, Gontova TM, Gubar SM, Ilyinska NI. Terms of procurement of medicinal plant raw materials of tansy (Tanacetum vulgare L.): inform. letter about innovations in the health care system № 130. 2016;20:5.

[6] Feduraev P, Chupakhina G, Maslennikov P, Tacenko N, Skrypnik L. Variation in Phenolic Compounds Content and Antioxidant Activity of Different Plant Organs from Rumex crispus L. and Rumex obtusifolius L. at Different Growth Stages. Antioxidants. 2019;8(7):237-245.

[7] Awang VC, Dawson BA, Kindack DG, Crompton CW, Heptinstall S. Parthenolide Content of Feverfew (Tanacetum parthenium) Assessed by Hplc and $1 \mathrm{H}-\mathrm{nmr}$ Spectroscopy. J. Nat. Prod. 1991;54,6:1516-1521.
[8] Hendricks H, Anderson-Wildeboer $\mathrm{Y}$, Engels G, Bos R, Woerdenbag $\mathrm{H}$. The Content of Parthenolide and its Yield per Plant During the Growth of Tanacetum parthenium. Planta Medica. 1997;63(4):356-359.

[9] Avula B, Navarrete A, Joshi VC, Khan IA. Quantification of parthenolide in Tanacetum species by LC-UV/LC-MS and microscopic comparison of Mexican/US feverfew samples. Pharmazie. 2006;61(7):590-594.

[10] European Pharmacopoeia 9th ed. Strasbourg: European Department for the Quality of Medicines; 2013:1355-1356.

[11] British Pharmacopoeia. British Pharmacopoeia commission. London: The Stationery Office. 2009;3:6982-6984.

[12] Upton R. American Herbal Pharmacopoeia: botanical pharmacognosy-microscopic characterization of botanical medicines. «CRC Press». 2011:635-638.

[13] United States Pharmacopeia 30-th Edition Suppl USP30-NF25. 2007:925.

[14] State Pharmacopoeia of Ukraine. State Enterprise: Scientific and Expert Pharmacopoeial Centre. 2ed. Kharkov. 2014:732. 